\title{
The Efficacy of Mizoribine (Inosine Monophosphate Dehydrogenase Inhibitor) for ANCA-Associated Vasculitis with Hepatitis B Virus Carrier
}

\author{
Jun Muratsu, ${ }^{1}$ Atsuyuki Morishima, ${ }^{1}$ Masayoshi Kukida, ${ }^{1}$ Anzu Tanaka, ${ }^{1}$ \\ Shigeki Fujita, ${ }^{2}$ and Katsuhiko Sakaguchi ${ }^{1}$ \\ ${ }^{1}$ Department of Nephrology and Hypertension, Sumitomo Hospital, 5-3-20 Kitaku Nakanoshima, Osaka 530-0005, Japan \\ ${ }^{2}$ Department of Pathology, Sumitomo Hospital, 5-3-20 Kitaku Nakanoshima, Osaka 530-0005, Japan \\ Correspondence should be addressed to Jun Muratsu,jm27252725@yahoo.co.jp
}

Received 4 November 2012; Accepted 22 November 2012

Academic Editors: M. Hummel, A. M. Mansour, M. M. Nogueras, Y. Nozaki, M. T. Perez-Gracia, A. E. Tebo, and A. Vojdani

Copyright ( $\odot 2012$ Jun Muratsu et al. This is an open access article distributed under the Creative Commons Attribution License, which permits unrestricted use, distribution, and reproduction in any medium, provided the original work is properly cited.

A 42-year-old female who was an asymptomatic carrier of hepatitis B virus (HBV) was diagnosed with antineutrophil cytoplasm antibody- (ANCA-) associated vasculitis and was induced to remission with $30 \mathrm{mg} / \mathrm{day}$ prednisolone nine years ago. Four years ago, she suffered recurrence of ANCA-associated vasculitis and with $30 \mathrm{mg} /$ day prednisolone was induced to remission. This time, laboratory data showed 3-fold increase in myeloperoxidase antineutrophil cytoplasmic antibody (MPO-ANCA) levels. Administration of $30 \mathrm{mg} /$ day prednisolone was started. Three days later, she was admitted to our hospital suffering from fatigue. After admission, urinalysis showed glomerular hematuria. Despite administration of $30 \mathrm{mg} /$ day prednisolone, MPO-ANCA titer had been of high level, ranging from 42 to $83 \mathrm{EU}$ for 2.5 months. Furthermore, the adverse effects of steroid were seen. We decided the tapering of prednisolone $(25 \mathrm{mg} / \mathrm{day})$ and the start of mizoribine (4-carbamoyl-1- $\beta$-D-ribofuranosyl imidazolium-5-olate) administration. After mizoribine treatment, MPO-ANCA titer was decreased without any mizoribine-related adverse effects. Six months later, MPO-ANCA titer was decreased to normal levels and she was induced to clinical remission without reactivation of HBV. We describe the effectiveness of mizoribine for the ANCA-associated vasculitis complicated with HBV-carrier.

\section{Introduction}

The common treatment for antineutrophil cytoplasm antibody- (ANCA-) associated vasculitis is oral cyclophosphamide-corticosteroid combination therapy. However, there are some reports that cyclophosphamide-corticosteroid combination therapy has serious complications such as increased risk of infection, leucopenia, osteoporosis, diabetes, and sterility and malignancy [1-4]. Reactivation of hepatitis B virus (HBV) replication is one of complications in patients with chronic HBV infection who receive immunosuppressive therapy [5].

Mizoribine (4-carbamoyl-1- $\beta$-D-ribofuranosyl imidazololium-5-olate), a purine synthesis inhibitor, has an immunosuppressive effect equivalent to that of azathioprine, but with less hepatic toxicity and myelosuppression [6].
Mizoribine and mycophenolic acid inhibit the rate-limiting enzyme inosine monophosphate dehydrogenase (IMPDH) in the de novo pathway of purine biosynthesis. It was reported that IMPDH inhibitors have potential antiviral effect in vitro and inhibited HBV replication with cultures of primary human hepatocytes, HepG2 2.2.15 cells [7-12].

There have been some reports that mizoribine is useful not only as a preemptive treatment to prevent relapse, but as also an aggressive strategy to induce the remission of relapsed ANCA-associated renal vasculitis $[13,14]$. However, there have not been any reports about the effectiveness of mizoribine in ANCA-associated renal vasculitis with HBV carrier. Herein, we describe the successful treatment with mizoribine for the case of the ANCA-associated renal vasculitis complicated with HBV carrier who was induced to remission without reactivation of $\mathrm{HBV}$. 


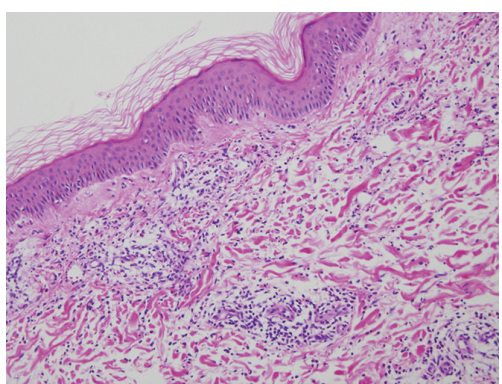

(a)

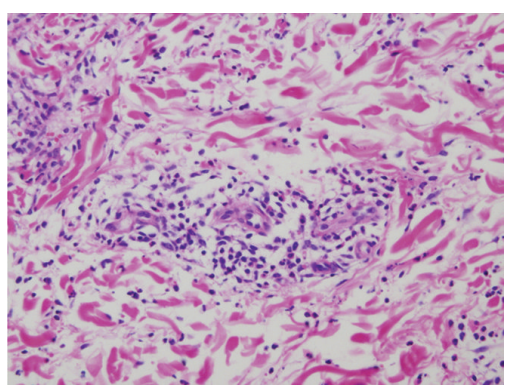

(b)

FIGURE 1: Skin biopsy showed findings of leukocytoclastic vasculitis (A, B H\&E stain; A $\times 20$; B $\times 40$ ).

\section{Case Presentation}

A 42-year-old Japanese female experienced glomerular hematuria, bilateral pedal purpura, and arthralgia nine years ago. Elevation of MPO-ANCA titer and serum creatinine levels was shown. Percutaneous renal biopsy was performed. Nine glomeruli were observed by light microscopy. Five of them were totally obsolescent, and the rest were also collapsing to some extent. Two glomerulus showed cellular crescentic glomerulonephritis. Glomerular deposition of IgA, IgM, IgG, C1q, C3, and C4 was negative. In addition, skin biopsy was performed, which showed leukocytoclastic vasculitis (Figures 1(a) and 1(b)). Thus, she was diagnosed with antineutrophil cytoplasm antibody- (ANCA-) associated vasculitis. Her past medical histories included asymptomatic carrier of hepatitis B virus (HBV) in childhood. Administration of lamivudine was started. She was induced to remission with $30 \mathrm{mg} /$ day prednisolone. Prednisolone had been gradually tapered to $5 \mathrm{mg}$. Elevation of aspartate aminotransferase and alanine aminotransferase had not been seen. Four years ago, the ANCA-associated vasculitis relapsed and was induced to remission $30 \mathrm{mg} /$ day prednisolone. Prednisolone had been gradually tapered to $12 \mathrm{mg}$. HBV-DNA had been from 3.4 to $4.5 \log (10)$ IU. Elevation of aspartate aminotransferase and alanine aminotransferase was not seen.

This time, laboratory data showed normal serum creatinine levels and, however, 3-fold increase in myeloperoxidase antineutrophil cytoplasmic antibody (MPO-ANCA) levels (82 EU). We speculated recurrence of the ANCA-associated vasculitis. Administration of $30 \mathrm{mg} /$ day prednisolone was started. Three days later, she was admitted to our hospital suffering from fatigue. On admission, her pulse rate was

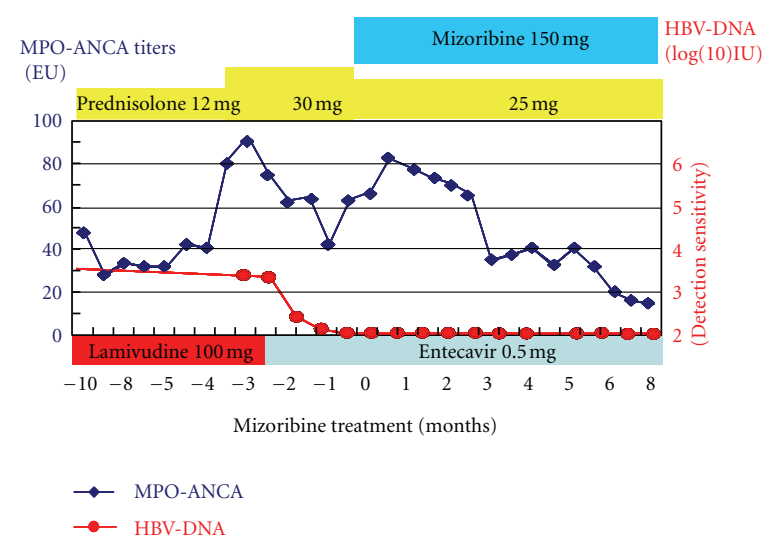

FIgUre 2: Time course plots of the MPO-ANCA levels and HBVDNA. MPO-ANCA: myeloperoxidase antineutrophil cytoplasmic antibody; $H B V-D N A$ : Hepatitis B Virus-DNA.

$76 / \mathrm{min}$ regular, blood pressure was $130 / 84 \mathrm{mmHg}$, and body temperature was $36.2^{\circ} \mathrm{C}$. Her consciousness was clear. Her bulbar conjunctiva was not icteric, and the palpebral conjunctiva was not pale. On auscultation, her lungs and heart were normal. Cough, pulmonary alveolar hemorrhage, and gastrointestinal bleeding were not observed. On palpation, hepatosplenomegaly and ascites were not observed. She did not have any neurological abnormalities. In addition, purpura, rash, arthralgia, myalgia, edema, or oral and genital ulceration were not found. Table 1 shows laboratory data at the admission. Laboratory data showed myeloperoxidase antineutrophil cytoplasmic antibody (MPO-ANCA) levels and showed 3-fold increase, $93 \mathrm{EU}$. HBs antigen was positive, and HBV-DNA level was $3.4 \log (10)$ IU. Her chest X-ray and echocardiography were normal and electrocardiography had no problem. Abdominal ultrasonography showed that liver was not atrophy. After admission, a urinalysis indicated $+/-$ proteinuria and a $3+$ occult blood reaction with 21-50 red blood cells per high-power field. Her 24-hour urinary protein excretion was $0.03 \mathrm{~g}$. Her urine volume was $2300 \mathrm{~mL} /$ day. Figure 2 shows time course plots of the MPOANCA levels and HBV-DNA. Despite administration of $30 \mathrm{mg} /$ day prednisolone for 2.5 months, MPO-ANCA titers increased and hematuria had been seen without elevation of serum creatinine levels. Furthermore, the adverse effects of steroid, such as moon face, insomnia, and femur head necrosis, were seen. Because she strongly desired pregnancy in the future, we did not start cyclophosphamide. We decided tapering of prednisolone ( $25 \mathrm{mg}$ /day) and start of mizoribine (4-carbamoyl-1- $\beta$-D-ribofuranosyl imidazololium-5-olate) (150 mg/day) administration. Before the start of mizoribine, HBV-DNA was $2.5 \log (10)$ IU and elevation of aspartate aminotransferase and alanine aminotransferase was not seen. Because HBV-DNA was detectable and longer duration (>12 months) of treatment for HBV and ANCA-associated renal vasculitis is anticipated, we changed lamivudine to entecavir before the start of mizoribine administration. We monitored serum concentration of mizoribine (Figure 3 ). Trough level of mizoribine was $0 \mu \mathrm{g} / \mathrm{mL}$, after 2 hours 
TABLE 1: Laboratory data on admission.

\begin{tabular}{|c|c|}
\hline \multicolumn{2}{|l|}{ Complete blood count } \\
\hline White blood cell count & $12100 / \mu \mathrm{L}$ \\
\hline Red blood cell count & $354 \times 10^{4} / \mu \mathrm{L}$ \\
\hline Hemoglobin & $11.9 \mathrm{~g} / \mathrm{dL}$ \\
\hline Hematocrit & $35.8 \%$ \\
\hline Platelets & $33.1 \times 10^{4} / \mu \mathrm{L}$ \\
\hline \multicolumn{2}{|l|}{ Blood chemical } \\
\hline Aspartate aminotransferase & $23 \mathrm{IU} / \mathrm{L}$ \\
\hline Alanine aminotransferase & $12 \mathrm{IU} / \mathrm{L}$ \\
\hline Alkaline phosphatase & $117 \mathrm{IU} / \mathrm{L}$ \\
\hline Lactate dehydrogenase & $202 \mathrm{IU} / \mathrm{L}$ \\
\hline$\gamma$-GTP & $24 \mathrm{IU} / \mathrm{L}$ \\
\hline Total bilirubin & $0.7 \mathrm{mg} / \mathrm{dL}$ \\
\hline Creatine phosphokinase & $77 \mathrm{IU} / \mathrm{L}$ \\
\hline Total cholesterol & $312 \mathrm{mg} / \mathrm{dL}$ \\
\hline Triglyceride & $69 \mathrm{mg} / \mathrm{dL}$ \\
\hline Sodium & $136 \mathrm{mEq} / \mathrm{L}$ \\
\hline Chloride & $99 \mathrm{mEq} / \mathrm{L}$ \\
\hline Potassium & $4.5 \mathrm{mEq} / \mathrm{L}$ \\
\hline Uric acid & $4.2 \mathrm{mg} / \mathrm{dL}$ \\
\hline Blood urea nitrogen & $13 \mathrm{mg} / \mathrm{dL}$ \\
\hline Creatinine & $0.56 \mathrm{mg} / \mathrm{dL}$ \\
\hline Total protein & $6.7 \mathrm{~g} / \mathrm{dL}$ \\
\hline Albumin & $4.6 \mathrm{~g} / \mathrm{dL}$ \\
\hline C-reactive protein & $0.04 \mathrm{mg} / \mathrm{dL}$ \\
\hline Fasting plasma glucose & $79 \mathrm{mg} / \mathrm{dL}$ \\
\hline Hemoglobin A1c & $5.0 \%$ \\
\hline KL-6 & $151 \mathrm{U} / \mathrm{mL}$ \\
\hline \multicolumn{2}{|l|}{ Immunology } \\
\hline Immunoglobulin $\mathrm{G}$ & $782 \mathrm{mg} / \mathrm{dL}$ \\
\hline Immunoglobulin A & $145 \mathrm{mg} / \mathrm{dL}$ \\
\hline Immunoglobulin $\mathrm{M}$ & $48 \mathrm{mg} / \mathrm{dL}$ \\
\hline Complement titer (CH50) & $36.9 \mathrm{U} / \mathrm{mL}$ \\
\hline Complement C3 & $84 \mathrm{mg} / \mathrm{dL}$ \\
\hline Complement C4 & $18 \mathrm{mg} / \mathrm{dL}$ \\
\hline Antinuclear antibody & $<40$ \\
\hline HBs antigen & $(+)$ \\
\hline HBe antigen & $(-)$ \\
\hline HBe antibody & $(+)$ \\
\hline HBV-DNA & $3.4 \log (10) \mathrm{IU}$ \\
\hline $\mathrm{HCV}$-antibody & $(-)$ \\
\hline \multicolumn{2}{|l|}{ Coagulation } \\
\hline APTT & 25.1 second \\
\hline PT-INR & 0.80 \\
\hline \multicolumn{2}{|l|}{$<$ ELISA $>$} \\
\hline MPO-ANCA & $93 \mathrm{EU}$ \\
\hline PR3-ANCA & $<10 \mathrm{EU}$ \\
\hline \multicolumn{2}{|l|}{ Urinalysis } \\
\hline $\mathrm{pH}$ & 7.0 \\
\hline Specific gravity & 1.010 \\
\hline Glucose & $(-)$ \\
\hline Protein & $(-)$ \\
\hline
\end{tabular}

TABLE 1: Continued.

\begin{tabular}{lc}
\hline Cast & Hyaline cast $(+)$ \\
Erythrocytes & $1-5 / \mathrm{HPF}$ \\
Leukocytes & $1-5 / \mathrm{HPF}$ \\
\hline$\gamma$-GTP: gamma-glutamyl transpeptidase, PR3-ANCA: proteinase-3 anti- \\
neutrophil cytoplasmic antibody, MPO-ANCA: myeloperoxidase anti-neu- \\
trophil cytoplasmic antibody, APTT: activated partial thromboplastin time, \\
PT-INR: prothrombin time-international normalized ratio.
\end{tabular}

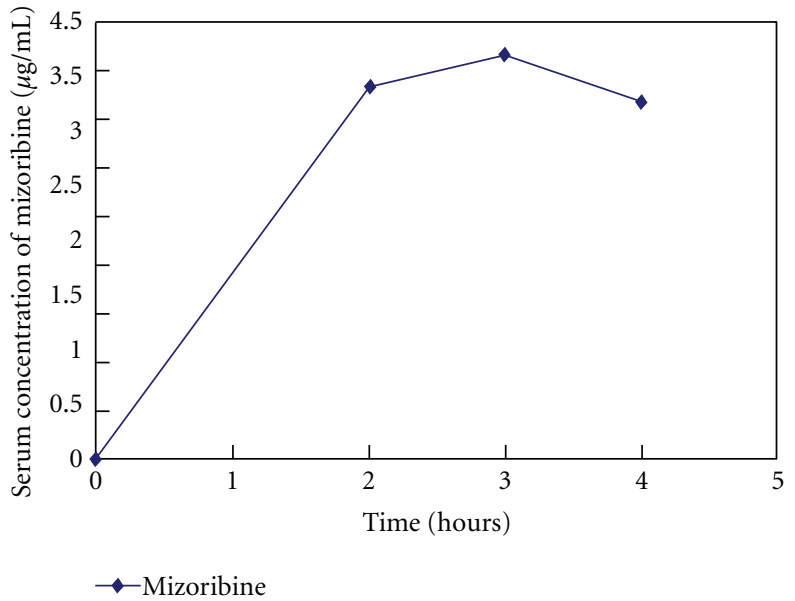

FIGURE 3: Serum concentration-time curve of mizoribine in this case.

the level was $3.82 \mu \mathrm{g} / \mathrm{mL}$, after 3 hours the level (peak level of mizoribine) was $4.17 \mu \mathrm{g} / \mathrm{mL}$, and after 4 hours the level was $3.67 \mu \mathrm{g} / \mathrm{mL}$. After mizoribine treatment, MPO-ANCA titer was decreased without any mizoribine-related adverse effects. Six months later, hematuria and fatigue had not been shown. She was induced to clinical remission without reactivation of HBV. Elevation of MPO-ANCA titers has not been presented for one year.

\section{Discussion}

We describe a case of the ANCA-associated vasculitis with HBV carrier who was induced remission with mizoribine without reactivation of $\mathrm{HBV}$.

In general, the treatment of relapsed ANCA-associated vasculitis is based on cyclophosphamide and high-dose corticosteroids. However, high-dose corticosteroids are of high risk for HBV replication because HBV-DNA contains a glucocorticoid responsive element [15]. Reactivation of hepatitis B virus (HBV) replication is a well-recognized complication in patients with chronic HBV infection who receive immunosuppressive therapy [5]. However, it was reported that corticosteroid is relatively safe under administration of entecavir [16]. No reports have been described if mizoribine caused HBV replication and fulminant hepatitis.

Mizoribine has an immunosuppressive effect equivalent to that of azathioprine; however, it shows less hepatic toxicity and myelosuppression [6]. Mizoribine has recently been proved clinically effective and relatively safe for the treatment of nephritic syndrome, lupus nephritis, IgA nephropathy, 
and ANCA-associated renal vasculitis [14, 17-19]. The administration should also only be done in facilities where the blood level of mizoribine can be monitored. It is important to monitor serum concentration of mizoribine because mizoribine is excreted through kidney. There have been some reports that more than $5 \mu \mathrm{g} / \mathrm{mL}$ of mizoribine trough level induce hepatic dysfunction [6]. Mizoribine showed an inhibition of $50 \%$ on human mixed-lymphocyte reaction at a concentration of about $1 \mu \mathrm{g} / \mathrm{mL}$.

Mizoribine and mycophenolic acid inhibit the ratelimiting enzyme inosine monophosphate dehydrogenase (IMPDH) in the de novo pathway of purine biosynthesis. It has been reported that mycophenolic acid inhibits the replication of human immunodeficiency virus (HIV) in vitro by depletion of the deoxynucleoside triphosphate substrate of the reverse transcriptase, thus blocking formation of the viral DNA [7]. It was reported that in vitro mycophenolic acid inhibited HBV replication. Experiments were performed using cultures of primary human hepatocytes, HepG2 2.2.15 cells in the report [8]. Inhibition of IMPDH reduces the level of intracellular guanine nucleotides required for adequate RNA and DNA synthesis. Therefore, IMPDH inhibitors have potential antiviral effect [9-12]. In addition, it was reported that mizoribine was able to suppress cytomegalovirus plaque formation dose dependently [20]. Thus, we speculate that mizoribine would inhibit HBV replication. However, there was no evidence that mizoribine inhibited $\mathrm{HBV}$ replication in vivo. Entecavir may suppress $\mathrm{HBV}$ replication in this case. This case revealed that mizoribine is safe for ANCAassociated renal vasculitis complicated with HBV carrier under administration of entecavir. It is important to consider mizoribine administration for ANCA-associated renal vasculitis with HBV carrier. However, we must take care of reactivation of $\mathrm{HBV}$ replication and monitor HBV-DNA.

In conclusion, mizoribine may be useful and safe for ANCA-associated vasculitis with HBV carrier. There is the possibility that mizoribine is one of the choices for the treatment of ANCA-associated renal vasculitis complicated with HBV carrier. Further experience is needed to confirm our conclusions.

\section{Conflict of Interests}

The authors have declared that no conflict of interests exists.

\section{References}

[1] J. Turnbull and L. Harper, "Adverse effects of therapy for ANCA-associated vasculitis," Best Practice and Research: Clinical Rheumatology, vol. 23, no. 3, pp. 391-401, 2009.

[2] H. Nawata, S. Soen, R. Takayanagi et al., "Guidelines on the management and treatment of glucocorticoid-induced osteoporosis of the Japanese Society for Bone and Mineral Research (2004)," Journal of Bone and Mineral Metabolism, vol. 23, no. 2, pp. 105-109, 2005.

[3] M. C. Park, Y. B. Park, S. Y. Jung, I. H. Chung, K. H. Choi, and S. K. Lee, "Risk of ovarian failure and pregnancy outcome in patients with lupus nephritis treated with intravenous cyclophosphamide pulse therapy," Lupus, vol. 13, no. 8, pp. 569574, 2004.
[4] J. E. Hader, L. Marzella, R. A. M. Myers, S. C. Jacobs, and M. J. Naslund, "Hyperbaric oxygen treatment for experimental cyclophosphamide-induced hemorrhagic cystitis," Journal of Urology, vol. 149, no. 6, pp. 1617-1621, 1993.

[5] A. S. F. Lok, R. H. S. Liang, E. K. W. Chiu, K. L. Wong, T. K. Chan, and D. Todd, "Reactivation of hepatitis B virus replication in patients receiving cytotoxic therapy: report of a prospective study," Gastroenterology, vol. 100, no. 1, pp. 182-188, 1991.

[6] K. Sonda, K. Takahashi, K. Tanabe et al., "Clinical pharmacokinetic study of mizoribine in renal transplantation patients," Transplantation Proceedings, vol. 28, no. 6, pp. 3643-3648, 1996.

[7] H. Ichimura and J. A. Levy, "Polymerase substrate depletion: a novel strategy for inhibiting the replication of the human immunodeficiency virus," Virology, vol. 211, no. 2, pp. 554560, 1995.

[8] Z. J. Gong, S. De Meyer, C. Clarysse et al., "Mycophenolic acid, an immunosuppressive agent, inhibits HBV replication in vitro," Journal of Viral Hepatitis, vol. 6, no. 3, pp. 229-236, 1999.

[9] P. Franchetti and M. Grifantini, "Nucleoside and nonnucleoside IMP dehydrogenase inhibitors as antitumor and antiviral agents," Current Medicinal Chemistry, vol. 6, no. 7, pp. 599-614, 1999.

[10] E. Padalko, E. Verbeken, P. Matthys, J. L. Aerts, E. De Clercq, and J. Neyts, "Mycophenolate mofetil inhibits the development of Coxsackie B3-virus-induced myocarditis in mice," BMC Microbiology, vol. 3, article 25, 2003.

[11] M. C. Livonesi, R. L. Moro De Sousa, and L. T. Moraes Figueiredo, "In vitro study of antiviral activity of mycophenolic acid on Brazilian orthobunyaviruses," Intervirology, vol. 50, no. 3, pp. 204-208, 2007.

[12] W. Markland, T. J. Mcquaid, J. Jain, and A. D. Kwong, "Broadspectrum antiviral activity of the IMP dehydrogenase inhibitor VX- 497: a comparison with ribavirin and demonstration of antiviral additivity with alpha interferon," Antimicrobial Agents and Chemotherapy, vol. 44, no. 4, pp. 859-866, 2000.

[13] K. Hirayama, M. Kobayashi, Y. Hashimoto et al., "Treatment with the purine synthesis inhibitor mizoribine for ANCAassociated renal vasculitis," American Journal of Kidney Diseases, vol. 44, no. 1, pp. 57-63, 2004.

[14] Y. Nishioka, Y. Horita, M. Tadokoro et al., "Mizoribine induces remission of relapsed ANCA-associated renal vasculitis," Nephrology Dialysis Transplantation, vol. 21, no. 4, pp. 10871088, 2006.

[15] A. L. Cheng, C. A. Hsiung, I. J. Su et al., "Steroid-free chemotherapy decreases risk of hepatitis B virus (HBV) reactivation in HBV-carriers with lymphoma," Hepatology, vol. 37, no. 6, pp. 1320-1328, 2003.

[16] A. S. F. Lok and B. J. McMahon, "Chronic hepatitis B," Hepatology, vol. 45, no. 2, pp. 507-539, 2007.

[17] K. Yoshioka, Y. Ohashi, T. Sakai et al., "A multicenter trial of mizoribine compared with placebo in children with frequently relapsing nephrotic syndrome," Kidney International, vol. 58, no. 1, pp. 317-324, 2000.

[18] K. Kaneko, "Mizoribine for childhood IgA nephropathy," Nephron, vol. 83, no. 4, pp. 376-377, 1999.

[19] K. Hirayama, M. Kobayashi, Y. Hashimoto et al., "Treatment with the purine synthesis inhibitor mizoribine for ANCAassociated renal vasculitis," American Journal of Kidney Diseases, vol. 44, no. 1, pp. 57-63, 2004. 
[20] T. Kuramoto, T. Daikoku, Y. Yoshida et al., "Novel anticytomegalovirus activity of immunosuppressant mizoribine and its synergism with ganciclovir," Journal of Pharmacology and Experimental Therapeutics, vol. 333, no. 3, pp. 816-821, 2010. 


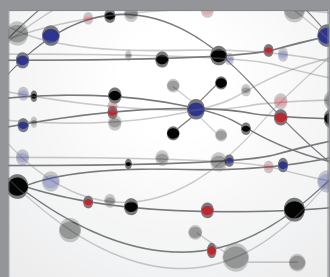

The Scientific World Journal
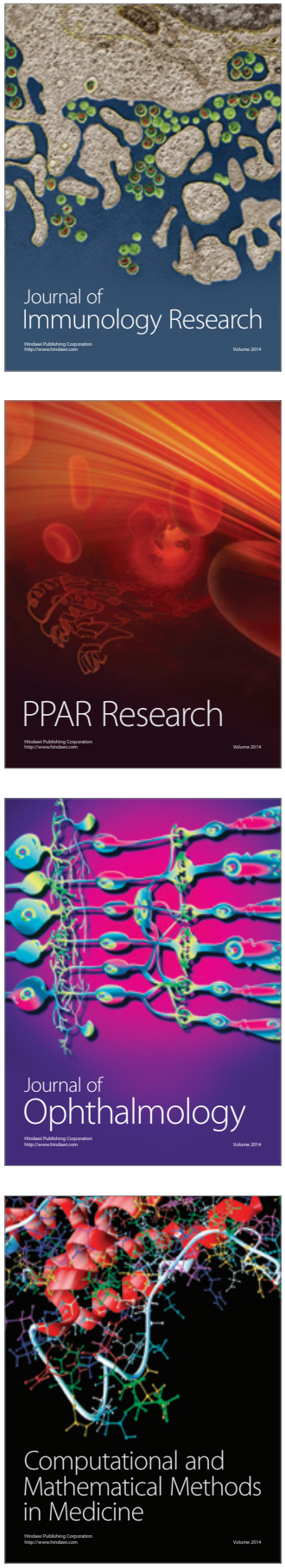

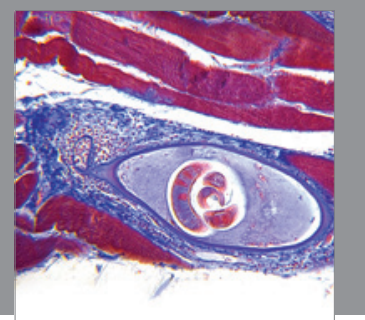

Gastroenterology

Research and Practice
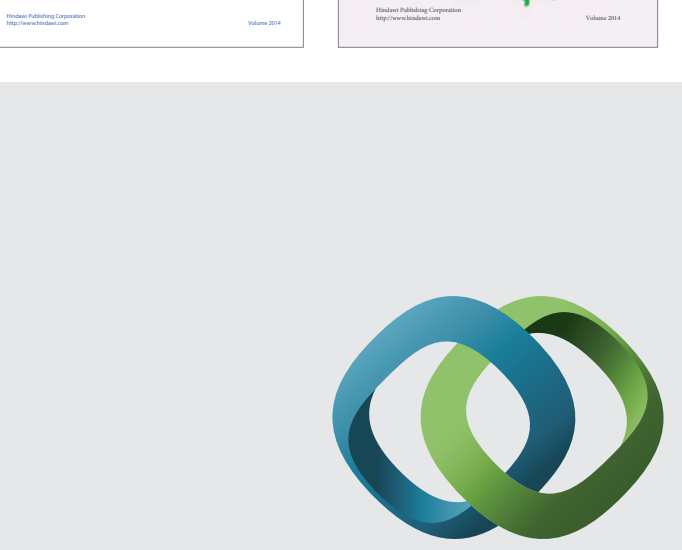

\section{Hindawi}

Submit your manuscripts at

http://www.hindawi.com
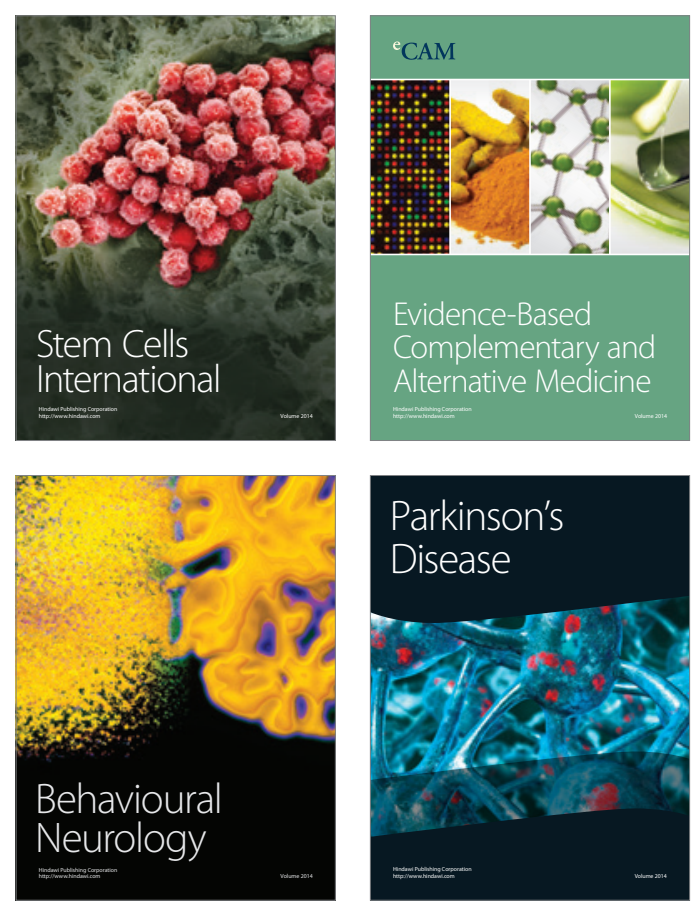

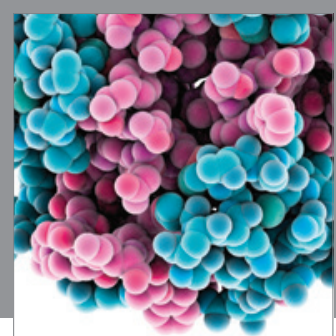

Journal of
Diabetes Research

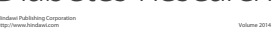

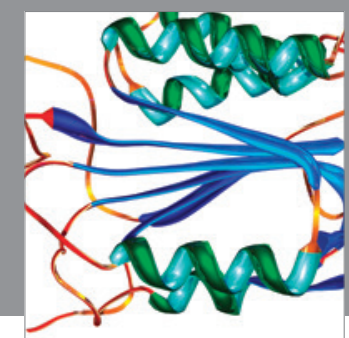

Disease Markers
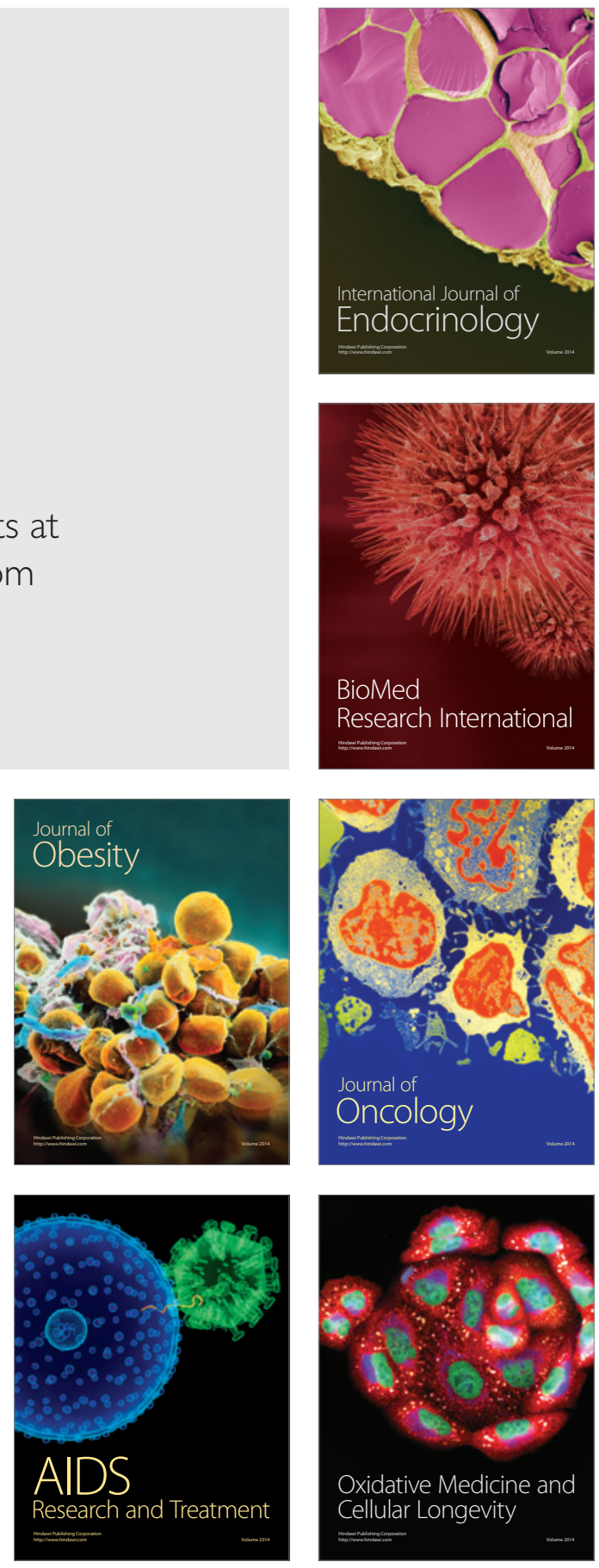